\title{
Fractionation of hydrogen isotopes in crystal water of copper chloride dihydrate-saturated solution-water vapor system
}

\author{
MASAHISA KAKIUCHI* \\ Department of Chemistry, Faculty of Science, Gakushuin University, \\ 1-5-1 Mejiro, Toshima-ku, Tokyo 171-8588, Japan
}

(Received June 4, 2001; Accepted July 2, 2001)

\begin{abstract}
The $\mathrm{D} / \mathrm{H}$ fractionation factors between the crystal water of copper chloride dihydrate and a saturated aqueous solution of copper(II) chloride, $\alpha_{\mathrm{CW} \text {-st.sol }}$, and between the saturated aqueous solution and water vapor, $\alpha_{\text {st.sol-v }}$, were experimentally determined at $25^{\circ} \mathrm{C}$ in equilibrium. The observed values of $\alpha_{\mathrm{CW} \text {-st.sol }}$ and $\alpha_{\text {st.sol-V }}$, were $0.950 \pm 0.002$ and $1.052 \pm 0.001$, respectively.

The $\mathrm{D} / \mathrm{H}$ fractionation factor between the crystal water of copper chloride dihydrate and water vapor in equilibrium, $\alpha_{\mathrm{CW}-\mathrm{V}}$, was calculated to be $0.999 \pm 0.002$ from the observed values of $\alpha_{\mathrm{CW} \text {-st.sol }}$ and $\alpha_{\text {st.sol-V }}$, and is used to discuss $\mathrm{D} / \mathrm{H}$ fractionation in crystal water of crystalline hydrates. It is shown that such $\mathrm{D} / \mathrm{H}$ fractionation is better expressed by $\alpha_{\mathrm{CW}-\mathrm{V}}$ than by the conventionally used fractionation factor between crystal water and mother liquor, $\alpha_{\mathrm{CW} \text {-st.sol }}$, because $\alpha_{\mathrm{CW}-\mathrm{V}}$ represents the activity ratio, whereas $\alpha_{\mathrm{CW} \text {-st.sol }}$ is simply the concentration ratio.

Based on the results in this study, we consider that the coordination bond between divalent cupreous ions and oxygen atoms in water molecules and the hydrogen bond between crystal water and chlorine ions contribute substantially to the fractionation of hydrogen isotopes.
\end{abstract}

\section{INTRODUCTION}

The isotopic ratios of hydrogen and oxygen in hydrated water in natural hydrous minerals provide information regarding the source materials from which the hydrous minerals originated. However, due to isotopic fractionation during the formation of the hydrous minerals, the isotopic ratios may have changed depending on the process of mineral formation. In order to elucidate information on the process of formation and the original material of the hydrous minerals, knowledge of the isotopic fractionation factors in hydrous mineral-water systems is essential.

A numbers of researchers have determined $\mathrm{D} / \mathrm{H}$ fractionation factors for crystalline hydratewater systems (e.g., Barrer and Denny, 1964; Matsuo et al., 1972; Pradhananga and Matsuo, 1985; Horita, 1989). In most cases, fractionation factors are determined in the form $\alpha_{\mathrm{CW} \text {-st.sol }}$; the ratio of the isotopic concentration ratio in crystal water $(\mathrm{CW})$ to that in the mother liquor, which is made up the super-saturated solution (st.sol). As the isotopic activity coefficients of water in saturated solutions differ significantly depending on the solute species and concentration, as pointed out by Horita (1989), $\alpha_{\mathrm{CW} \text {-st.sol }}$ is not a comprehensive indicator of isotope fractionation for all crystalline hydrate-water systems.

A more appropriate indicator for comparing isotopic fractionation in a range of crystalline hydrate-water systems is the isotopic fractionation factor between crystal water $(\mathrm{CW})$ and water vapor (V) in equilibrium, $\alpha_{\mathrm{CW}-\mathrm{V}}$, which represents isotopic activity ratios (Kakiuchi, 1997a, 1999a, $1999 b)$. In addition, the use of $\alpha_{\mathrm{CW}-\mathrm{V}}$ is more convenient for calculating of isotopic fractionation factors by means of partition function ratio calcu-

*e-mail:860018@Gakushuin.ac.jp 
lations. Partition functions for the crystalline phase can be calculated from the vibrational frequencies determined from infrared and Raman spectra, and accurate vibrational frequencies for water vapor are available in literature. In principle, this means that the partition function ratios for crystalline hydrate-water vapor systems can be calculated relatively easily (Kakiuchi et al., 2001). However, accurate vibrational frequencies for water molecules in aqueous solutions have not as yet been obtained, making partition function ratios for crystalline hydrate-saturated solution systems difficult to obtain.

The purpose of this paper is (1) to present results for $\mathrm{D} / \mathrm{H}$ fractionation in the crystal watersaturated solution-water vapor system of copper(II) chloride at $25^{\circ} \mathrm{C}$, and (2) to propose the use of the fractionation factor between crystal water and water vapor in equilibrium, $\alpha_{\mathrm{CW}-\mathrm{V}}$, instead of using the conventional fractionation factor between crystal water and mother liquor, $\alpha_{\mathrm{CW} \text {-st.sol}}$.

\section{EXPERIMENTAL}

D/H fractionation factors in crystal water of hydrate-saturated solution-water vapor system

The equilibrium isotopic compositions of the crystal water of hydrate $(\mathrm{CW})$ saturated solution (st.sol) and water vapor (V) are shown in Fig. 1. The isotopic fractionation factors in the system; $\alpha_{\text {st.sol-v }}, \alpha_{\mathrm{CW}-\text { st.sol }}$ and $\alpha_{\mathrm{CW}-\mathrm{v}}$ are defined as:

$$
\begin{aligned}
& \alpha_{\text {st.sol-V }}=\mathrm{R}_{\mathrm{L}}{ }^{\text {st.sol } / \mathrm{R}_{\mathrm{V}}}{ }^{\text {st.sol }} \\
& \alpha_{\mathrm{CW} \text {-st.sol }}=\mathrm{R}_{\mathrm{CW}} / \mathrm{R}_{\mathrm{L}}{ }^{\text {st.sol }} \\
& \alpha_{\mathrm{CW}-\mathrm{V}}=\mathrm{R}_{\mathrm{CW}} / \mathrm{R}_{\mathrm{V}}{ }^{\text {st.sol }}
\end{aligned}
$$

where $\mathrm{R}$ is the $\mathrm{D} / \mathrm{H}$ ratio and subscript $\mathrm{L}$ denotes liquid phase.

In the case of pure water ( $\mathrm{pw}$ ), the fractionation factor between the liquid and vapor phases, $\alpha_{\mathrm{pw}-\mathrm{V}}$, is expressed as:

$$
\alpha_{\mathrm{pw}-\mathrm{V}}=\mathrm{R}_{\mathrm{L}}^{\mathrm{pw}} / \mathrm{R}_{\mathrm{V}}^{\mathrm{pw}}
$$

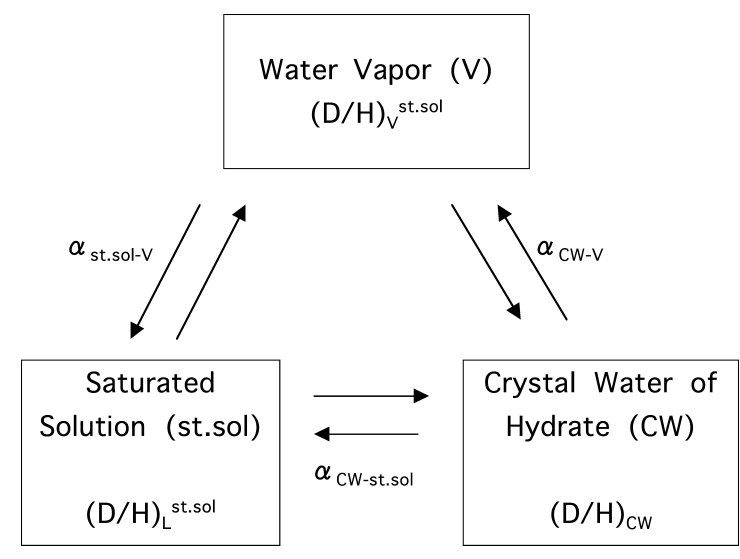

Fig. 1. Fractionation factors in water vapor (V)-saturated solution (st.sol)-crystal water $(C W)$ system in crystalline hydrates.

The value of $\alpha_{\mathrm{pw}-\mathrm{V}}$ at $25^{\circ} \mathrm{C}$ is 1.078 (Kakiuchi and Matsuo, 1979).

In order to compare $\alpha_{\text {st.sol-v }}$ with $\alpha_{\mathrm{pw}-\mathrm{V}}$, the ratio of the fractionation factors at a saturation point, $\beta_{\text {st.sol }}$, is introduced, defined as:

$$
\begin{aligned}
\beta_{\text {st.sol }} & =\alpha_{\text {st.sol-V }} / \alpha_{\text {pw-V }} \\
& =\left(\mathrm{R}_{\mathrm{L}}{ }^{\text {st.sol }} / \mathrm{R}_{\mathrm{V}}{ }^{\text {st.sol }}\right) /\left(\mathrm{R}_{\mathrm{L}}{ }^{\mathrm{pw}} / \mathrm{R}_{\mathrm{V}}{ }^{\mathrm{pw}}\right) .
\end{aligned}
$$

When identical water is used for pure water and the saturated solution, $\mathrm{R}_{\mathrm{L}}{ }^{\text {st.sol }}$ and $\mathrm{R}_{\mathrm{L}}{ }^{\mathrm{pw}}$ in Eq. (5') are the same. In this case, Eq. $\left(5^{\prime}\right)$ becomes:

$$
\beta_{\text {st.sol }}=\mathrm{R}_{\mathrm{V}}{ }^{\mathrm{pw}} / \mathrm{R}_{\mathrm{V}}{ }^{\text {st.sol }} \text {. }
$$

The value of $\beta_{\text {st.sol }}$ can be obtained by measuring the $\mathrm{D} / \mathrm{H}$ ratio of water vapor equilibrated with pure water and that of water vapor equilibrated with the saturated solution. In this study, the $\mathrm{H}_{2}$ equilibration technique was applied, according to an experimental method essentially identical to that described in previous papers (Kakiuchi, 1988, 1994, 1997b).

The fractionation factor between the crystal water of hydrate and water vapor, $\alpha_{\mathrm{CW}-\mathrm{V}}$, can be obtained from Eqs. (1) and (2) as follows:

$$
\alpha_{\mathrm{CW}-\mathrm{V}}=\alpha_{\text {st.sol-v }} \alpha_{\mathrm{CW} \text {-st.sol }}
$$


From Eq. (5), $\alpha_{\text {st.sol-v }}$ can be calculated from the values of $\alpha_{\mathrm{pw}-\mathrm{V}}$ and $\beta_{\text {st.sol }}$. Then, Eq. (7) becomes:

$\alpha_{\mathrm{CW}-\mathrm{V}}=\alpha_{\text {st.sol-v}} \alpha_{\mathrm{CW} \text {-st.sol }}=\alpha_{\mathrm{pw}-\mathrm{V}} \beta_{\text {st.sol }} \alpha_{\mathrm{CW} \text {-st.sol}}$.

The D/H fractionation factor between the crystal water of copper chloride dihydrate and water vapor can be obtained from the measured values of $\beta_{\text {st.sol }}$ and $\alpha_{\mathrm{CW} \text {-st.sol }}$ using Eq. (8).

\section{Synthesis of copper chloride dihydrate}

Reagent-grade anhydrous $\mathrm{CuCl}_{2}$ salt was thoroughly dried in a vacuum at $100^{\circ} \mathrm{C}$ for a few hours prior to dissolution. The salt was then dissolved in distilled water with known isotope composition. In order to avoid any change in the isotopic composition of the mother liquor caused by fractional crystallization, a slightly supersaturated solution was prepared by dissolving the dried anhydrous salt.

Single crystals of copper chloride dihydrate were synthesized at $25.0^{\circ} \mathrm{C}$ by the following two methods. Method A: Two flasks, connected vertically, were immersed in a water bath regulated at $25.0^{\circ} \mathrm{C}$. The solution in the upper flask maintained $5^{\circ} \mathrm{C}$ higher by a heater. The solution was circulated using a $2 \mathrm{ml} / \mathrm{min}$ pump, and the solution was slowly transferred from the upper flask to the lower flask. The single crystals were grown in the bottom of the lower flask. Method B: A supersaturated solution was added to a stoppered flask immersed in a water bath maintained at $25.0^{\circ} \mathrm{C}$. Single crystals were grown under static conditions.

After the crystalline hydrate of copper chloride dihydrate was grown, the solution was then filtered, and the single crystals were dried by pressing between filter papers. The crystals were gathered and stored in an airtight container.

\section{Isotopic analysis for $\beta_{\text {st.sol }}$ determination}

The fractionation factor between pure water and the saturated solution at $25.0^{\circ} \mathrm{C}, \beta_{\text {st.sol }}$ was obtained by the $\mathrm{H}_{2}$-equilibration technique using a hydrophobic platinum catalyst (Ohsumi and Fujino, 1986; Horita et al., 1989; Kakiuchi, 1988,
1994, 1997b). The experimental method used here was essentially identical to that used and described for $\beta$ determinations between pure water and aqueous solutions in previous papers (Kakiuchi, 1988, 1994, 1997b). The reagent-grade anhydrous $\mathrm{CuCl}_{2}$ salt used for this experiment was also thoroughly dried in a vacuum at $100^{\circ} \mathrm{C}$ for a few hours prior to dissolution.

In order to facilitate the measurement of the $\mathrm{D} / \mathrm{H}$ ratios for hydrogen gas using a mass spectrometer designed for natural abundance measurements, the deuterium content of water was adjusted to a $\mathrm{D} / \mathrm{H}$ ratio of about $5.8 \times 10^{-4}$. The $\mathrm{D} / \mathrm{H}$ ratio of hydrogen gas in equilibrium with the deuterium-doped water was about $1.5 \times 10^{-4}$, as indicated by the fractionation factor of 3.81 between liquid pure water and hydrogen gas at $25^{\circ} \mathrm{C}$ (Rolston et al., 1976). In order to prevent the precipitation of crystalline hydrates, the concentration of dissolved salt must be maintained just below saturation; in this case saturation occurs at $5.6 \mathrm{~mol} / \mathrm{kg}$, calculated from the data in the literature (Linke, 1958). A $5.5 \mathrm{~mol} / \mathrm{kg} \mathrm{CuCl}_{2}$ near-saturated solution was then prepared gravimetrically by dissolving the dried anhydride salt in the deuterium-enriched water. As mentioned in previous papers (Kakiuchi, 1988, 1994, 1997b), the difference in the measured $\beta_{\text {st.sol }}$ value due to this 0.1 $\mathrm{mol} / \mathrm{kg}$ difference is thought to be negligible.

The equilibration apparatus in which the hydrogen gas and liquid water sample was stored was immersed in a water bath maintained at $25.0 \pm$ $0.1^{\circ} \mathrm{C}$, regulated using a thermostat. The time required for equilibration was established by repeated analyses of the isotopic composition of the hydrogen gas in contact with the saturated solution collected sequentially. Pure water required several hours to reach a constant isotopic composition, whereas the saturated solution took days.

After equilibration, the hydrogen gas was separated from the liquid phase and catalyst, followed by removal of the water vapor by cooling the sample with liquid nitrogen. The hydrogen gas was collected using a Toepler pump and subsequently analyzed for the $\mathrm{D} / \mathrm{H}$ ratio using a mass spectrometer. 
Isotopic analysis for $\alpha_{C W \text {-st.sol }}$ determination

The $\mathrm{H}_{2}$-equilibration technique was applied to the mother liquor and the crystal water of the copper chloride dihydrate synthesized by method A in order to obtain the $\alpha_{\mathrm{CW} \text {-st.sol }}$ value. The $\mathrm{D} / \mathrm{H}$ ratio of the mother liquor from which the crystals were grown was determined by analyzing the $\mathrm{D} / \mathrm{H}$ ratio of the hydrogen gas in equilibrium with the deuterium-doped water used to make up the solutions. Method A produced 10-15 g of $\mathrm{CuCl}_{2} 2 \mathrm{H}_{2} \mathrm{O}$ crystals, the largest of which were completely dehydrated at between 100 and $120^{\circ} \mathrm{C}$ in a vacuum over a few hours. About $2 \mathrm{~g}$ of crystal water was liberated and collected in a condensation trap maintained at liquid nitrogen temperature. The $\mathrm{D} / \mathrm{H}$ ratio of the crystal water was determined by analyzing the $\mathrm{D} / \mathrm{H}$ ratio of the hydrogen gas in equilibrium with the dehydrated water.

Method B produced 25-40 mg of single crystal $\mathrm{CuCl}_{2} 2 \mathrm{H}_{2} \mathrm{O}$ yielding 5-8 mg of crystal water on dehydration. The sample was heated for a few hours in a vacuum to ensure complete dehydration. The temperature was gradually raised to about $200^{\circ} \mathrm{C}$ using a silicon oil bath. The liberated water was collected in a Pyrex glass tube containing $c a .0 .4 \mathrm{~g}$ of pure zinc grains at liquid nitrogen temperature. Approximately $5 \mathrm{mg}$ of the condensed water was converted quantitatively into hydrogen gas at $430^{\circ} \mathrm{C}$ in a furnace (Ushiki and Kakiuchi, in preparation). This technique is a modification of the zinc batch methods proposed by Coleman et al. (1982) and Sudzuki (1987).

After the single crystals of copper chloride dihydrate were dehydrated, the samples were re- heated in a vacuum, and it was confirmed that there remained no further water to liberate. The hydrogen gas obtained by the two methods was collected using a Toepler pump, and the $\mathrm{D} / \mathrm{H}$ ratio was determined using a mass spectrometer.

\section{RESUlTS AND DISCUSSION}

$D / H$ fractionation factor $\beta_{\text {st.sol }}$ between the saturated solution and water vapor for $\mathrm{CuCl}_{2}$

The relative deviation of the $\mathrm{D} / \mathrm{H}$ ratio from the standard is given by the delta notation, defined as:

$$
\delta \mathrm{D}(\% o)=\left[\left(\mathrm{R}_{\text {sample }} / \mathrm{R}_{\text {standard }}\right)-1\right] \times 10^{3} .
$$

The standard used is the laboratory standard of a deuterium content of about $155 \mathrm{ppm}$.

For the $\mathrm{H}_{2}$-equilibration technique, the $\mathrm{D} / \mathrm{H}$ fractionation factor between the saturated solution and water vapor, $\beta_{\text {st.sol }}$, is defined analogously from Eq. (6) as:

$$
\beta_{\text {st.sol }}=\mathrm{R}_{\mathrm{V}}{ }^{\mathrm{pw}} / \mathrm{R}_{\mathrm{V}}{ }^{\text {st.sol }}=\mathrm{R}_{\mathrm{c}}{ }^{\mathrm{pw}} / \mathrm{R}_{\mathrm{c}}{ }^{\text {st.sol }}
$$

where $\mathrm{R}_{\mathrm{c}}{ }^{\mathrm{pw}}$ and $\mathrm{R}_{\mathrm{c}}{ }^{\text {st.sol }}$ are the corrected $\mathrm{R}_{\mathrm{c}}$ values for the hydrogen gas in equilibrium with the initial pure water and saturated solution, respectively (Kakiuchi, 1994, 1997b). Equation (6') can be rewritten as follows using the delta notation:

$\beta_{\text {st.sol }}=\left(1+10^{-3} \delta \mathrm{D}_{\mathrm{c}}{ }^{\mathrm{pw}}\right) /\left(1+10^{-3} \delta \mathrm{D}_{\mathrm{c}}{ }^{\mathrm{st} . \mathrm{sol}}\right)$.

The results for the $5.5 \mathrm{~mol} / \mathrm{kg} \mathrm{CuCl}{ }_{2}$ near-satu-

Table 1. Measured $\delta D_{c}^{\text {st.sol }}$ and $\delta D_{c}^{p w}$ values ( \pm 1 standard deviation) for near-saturated solution of $5.5 \mathrm{~mol} / \mathrm{kg}$ copper(II) chloride, $\beta_{\text {st.sol }}$ value calculated using Eq. (6"), published value of $\alpha_{p w-V}$ at $25^{\circ} \mathrm{C}$ by Kakiuchi and Matsuo (1979) and calculated value of $\alpha_{\text {st.sol-V }}$ at $25^{\circ} \mathrm{C}$. Values in parenthesis are the number of measurements.

\begin{tabular}{ccccc}
\hline$\delta \mathrm{D}_{\mathrm{c}}^{\text {stsol }}(\% o)$ & $\delta \mathrm{D}_{\mathrm{c}}^{\mathrm{pw}}(\%)$ & $\beta_{\text {stsol }}$ & $\alpha_{\mathrm{pw}-\mathrm{V}}$ & $\alpha_{\text {stsoo-V }}$ \\
\hline $24.9 \pm 0.3(6)$ & $0.4 \pm 0.3(5)$ & $0.976 \pm 0.001$ & $1.078 \pm 0.001$ & $1.052 \pm 0.001$ \\
\hline
\end{tabular}

$D / H$ ratios of hydrogen gas, $\delta D_{c}^{\text {st.sol }}$ and $\delta D_{c}^{p w}$, are expressed as $\delta D_{c}$ values relative to the laboratory standard. The precision of the $\beta_{\text {st.sol }}$ value was estimated based on the difference in the molality of the saturation point. 
rated solution at $25^{\circ} \mathrm{C}$ are presented in Table 1 . Each data point represents the averaged value of several measurements. The value obtained for $\delta \mathrm{D}_{\mathrm{c}}{ }^{\text {st.sol }}$ is higher than that for $\delta \mathrm{D}_{\mathrm{c}}{ }^{\mathrm{pw}}$, indicating that the $\mathrm{D} / \mathrm{H}$ ratio of hydrogen gas (water vapor) equilibrated with the saturated $\mathrm{CuCl}_{2}$ solution is higher than that of hydrogen gas (water vapor) equilibrated with pure water. In consideration of the concentration dependence of the $\beta$ value as mentioned in the experimental section, it can be concluded that the $\beta$ value of $5.5 \mathrm{~mol} / \mathrm{kg}, 0.976 \pm$ 0.001 , can be regarded as the $\beta_{\text {st.sol }}$ value.

In the case of the saturated solution, the fractionation factor between the saturated solution for $\mathrm{CuCl}_{2}$ and water vapor, $\alpha_{\text {st.sol-V }}$, can be obtained from the values of $\beta_{\text {st.sol }}$ and $\alpha_{\mathrm{pw}-\mathrm{V}}$ using Eq. (5). The value of $\alpha_{\mathrm{pw}-\mathrm{V}}$ at $25^{\circ} \mathrm{C}, 1.078$, has already been reported by Kakiuchi and Matsuo (1979). The value of $\alpha_{\text {st.sol-v }}$ calculated here is $1.052 \pm 0.001$, as presented in Table 1 .

D/H fractionation factor $\alpha_{C W-\text { st.sol }}$ between saturated solution and crystal water in $\mathrm{CuCl}_{2} 2 \mathrm{H}_{2} \mathrm{O}$

The fractionation factor between the saturated solution (mother liquor) and crystal water of copper chloride dihydrate in Eq. (2), $\alpha_{\mathrm{CW} \text {-st.sol }}$, can be rewritten using the delta notation in Eq. (9) as:

$$
\begin{aligned}
\alpha_{\mathrm{CW} \text {-st.sol }} & =\mathrm{R}_{\mathrm{CW}} / \mathrm{R}_{\mathrm{L}}{ }^{\text {st.sol }} \\
& =\left(1+10^{-3} \delta \mathrm{D}_{\mathrm{CW}}\right) /\left(1+10^{-3} \delta \mathrm{D}_{\mathrm{L}}^{\text {st.sol }}\right) .
\end{aligned}
$$

The fractionation factor at $25^{\circ} \mathrm{C}, \alpha_{\mathrm{CW} \text {-st.sol }}$, is calculated as $0.950 \pm 0.002$ (average). In Table 2, each data point represents the averaged value of several measurements. The value obtained for $\delta \mathrm{D}_{\mathrm{CW}}$ is lower than that of $\delta \mathrm{D}_{\mathrm{L}}^{\text {st.sol }}$, indicating that the $\mathrm{D} / \mathrm{H}$ ratio of crystal water of copper chloride dihydrate equilibrated with the saturated solution is lower than that of the mother liquor. It can be concluded from Table 2 that the $\alpha_{\mathrm{CW} \text {-st.sol }}$ value does not differ within experimental error over the range of synthesis methods and analysis used in the present work.

$D / H$ fractionation factor $\alpha_{C W-V}$ between crystal water of $\mathrm{CuCl}_{2} \mathrm{2H}_{2} \mathrm{O}$ and water vapor

By measuring the values of $\beta_{\text {st.sol }}$ and $\alpha_{\mathrm{CW} \text {-st.sol }}$ and by using the $\mathrm{D} / \mathrm{H}$ fractionation factor between pure water and water vapor, $\alpha_{\mathrm{pw}-\mathrm{V}}$, the $\mathrm{D} / \mathrm{H}$ fractionation factor between crystal water in $\mathrm{CuCl}_{2} 2 \mathrm{H}_{2} \mathrm{O}$ and water vapor, $\alpha_{\mathrm{CW}-\mathrm{V}}$, can be calculated using Eq. (8). The calculated value of $\alpha_{\mathrm{CW}-\mathrm{v}}$ at $25^{\circ} \mathrm{C}$ is $0.999 \pm 0.002$, which indicates that the $\mathrm{D} / \mathrm{H}$ ratio of crystal water of $\mathrm{CuCl}_{2} 2 \mathrm{H}_{2} \mathrm{O}$ is equal to that of water vapor within experimental error.

The $\mathrm{D} / \mathrm{H}$ fractionation factor between ice and pure liquid water at $0^{\circ} \mathrm{C}, \alpha_{\mathrm{CW} \text {-st.sol }}$, is 1.019 (Weston, 1955; O’Neil, 1968), and that between pure liquid water and water vapor at $0^{\circ} \mathrm{C}, \alpha_{\mathrm{pw}-\mathrm{V}}$, is 1.105 , as extrapolated according to the relation given by Kakiuchi and Matsuo (1979). The calculated fractionation factor between ice and water

Table 2. Measured values of $\delta D_{C W}$ and $\delta D_{L}^{\text {st.sol }}( \pm 1$ standard deviation) and $D / H$ fractionation factor between crystal water of copper chloride dihydrate $(\mathrm{CW})$ and saturated aqueous solu-

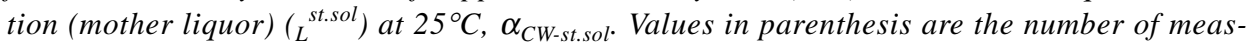
urements.

\begin{tabular}{cccccc}
\hline Method of precipitation & Method of analysis & Run & $\delta \mathrm{D}_{\mathrm{CW}}(\% o)$ & $\delta \mathrm{D}_{\mathrm{L}}{ }^{\text {stsol }}(\%)$ & $\alpha_{\mathrm{CW} \text {-stsol }}$ \\
\hline $\mathrm{A}$ & $\mathrm{H}_{2}$ & 1 & 19.6 & 77.9 & 0.9549 \\
& & 2 & -51.3 & -1.4 & 0.9500 \\
$\mathrm{~B}$ & $\mathrm{Zn}$ & 3 & $4.2 \pm 2.0(4)$ & $56.5 \pm 1.5(6)$ & $0.9505 \pm 0.0023$ \\
& & 4 & $1.5 \pm 0.6(2)$ & $54.8 \pm 1.1(5)$ & $0.9495 \pm 0.0011$ \\
\hline
\end{tabular}

Method of precipitation: A, Synthesized from circulating solution having the temperature gradient; B, Synthesized from supersaturated solution under static conditions.

Method of analysis: $\mathrm{H}_{2}$, Hydrogen gas-liquid water equilibration method established by Ohsumi and Fujino (1986), Horita et al. (1989) and Kakiuchi (1988, 1994, 1997b); Zn, Revised zinc batch method established by Ushiki and Kakiuchi (in preparation). 
Table 3. D/H fractionation factors and $\beta_{\text {st.sol }}$ values for crystalline hydrate systems and ice

\begin{tabular}{lccccccc}
\hline Temp. & Chemical formula & Molality*1 & $\alpha_{\text {pw-v }}{ }^{2}$ & $\beta_{\text {stsol }}$ & $\alpha_{\text {stsolv }}$ & $\alpha_{\text {CW-stsol }}$ & $\alpha_{\text {CW-v }}$ \\
\hline $25^{\circ} \mathrm{C}$ & $\mathrm{CuCl}_{2} 2 \mathrm{H}_{2} \mathrm{O}$ & 5.5 & 1.078 & 0.976 & 1.052 & 0.950 & 0.999 \\
& $\mathrm{CuSO}_{4} 5 \mathrm{H}_{2} \mathrm{O}$ & 1.4 & 1.078 & $0.999^{* 3}$ & 1.077 & $0.979^{* 4}$ & 1.054 \\
& $\mathrm{MgCl}_{2} 6 \mathrm{H}_{2} \mathrm{O}$ & 5.7 & 1.078 & $0.974^{* 3}$ & 1.050 & $0.980^{* 5}$ & 1.029 \\
& $\mathrm{MgSO}_{4} 7 \mathrm{H}_{2} \mathrm{O}$ & 3.0 & 1.078 & $1.021^{* 3}$ & 1.100 & $0.999^{* 6}$ & 1.100 \\
$0^{\circ} \mathrm{C}$ & $\mathrm{ICE}$ & - & 1.105 & 1 & 1.105 & $1.019^{* 7}$ & 1.126 \\
\hline
\end{tabular}

*1 Prepared molality near saturation point.

$*^{2}$ Kakiuchi and Matsuo (1979), extrapolated for $0^{\circ} \mathrm{C}$.

*3 Unpublished data.

${ }^{*}$ Kita and Matsuo (1981).

${ }^{*}$ Calculated from Horita (1989).

*6 Pradhananga and Matsuo (1985).

${ }^{* 7}$ Weston (1955) and O'Neil (1968).

vapor, $\alpha_{\mathrm{CW}-\mathrm{V}}$, at $0^{\circ} \mathrm{C}$ is then 1.126 . This value is relatively high, reflecting the fact that deuterium atoms preferentially enter the ice fraction during such segregation. At the elevated temperature in this study $\left(25.0^{\circ} \mathrm{C}\right)$, the $\mathrm{D} / \mathrm{H}$ ratio of crystal water of $\mathrm{CuCl}_{2} 2 \mathrm{H}_{2} \mathrm{O}$ is also lower than that of ice, indicating that the hydrogen bonding in the single crystal of $\mathrm{CuCl}_{2} 2 \mathrm{H}_{2} \mathrm{O}$ is significantly weaker than in ice.

In order to discuss this behavior quantitatively, the fractionation factors of copper chloride dihydrate, ice, and a number of other crystalline hydrates are listed in Table 3. It is clear that the difference in $\alpha_{\mathrm{CW}-\mathrm{V}}$ values is greater than that of $\alpha_{\mathrm{CW} \text {-st.sol }}$ values. Whereas the $\alpha_{\mathrm{CW} \text {-st.sol }}$ values for hydrates are less than unity, the $\beta_{\text {st.sol }}$ values sporadically deviate from unity, suggesting that the isotopic activities of the saturation solutions sporadically vary from the isotopic concentration of the solvent. We can conclude that it is better to use the $\mathrm{D} / \mathrm{H}$ ratio of water vapor than to use the $\mathrm{D} / \mathrm{H}$ ratio of the mother liquor.

As shown in Table 3, copper chloride dihydrate exhibits high degrees of hydrogen isotope fractionation, primarily attributable to the behavior of the coordination bond between divalent cupreous ions and oxygen atoms in water molecules and hydrogen bond between crystal water and chlorine ions.
The results presented in this study demonstrate that the fractionation factor between the crystal water of hydrates and water vapor, $\alpha_{\mathrm{CW}-\mathrm{V}}$, proposed as an alternative to the fractionation factor between crystal water and mother liquor, $\alpha_{\mathrm{CW} \text {-st.sol }}$, is a scale worth considering when discussing the hydrogen and oxygen isotope fractionation in crystalline hydrate-water systems. The proposed index, $\alpha_{\mathrm{CW}-\mathrm{V}}$, is invaluable for elucidating the temperature-, chemical species- and structure-dependent behavior of hydrogen and oxygen isotope fractionation in the crystal water of hydrates.

Acknowledgments-I am indebted to Mr. T. Suzuki and Mr. K. Kimishima for their participation in the early stage of this study. I wish to thank Prof. H. Nagasawa of Gakushuin University, for critical reading of the manuscript and helpful comments.

\section{REFERENCES}

Barrer, R. M. and Denny, A. F. (1964) Water in hydrates. part I. Fractionation of hydrogen isotopes by crystallization of salt hydrates. J. Chem. Soc. 46774684.

Coleman, M. L., Shepherd, T. J., Durham, J. J., Rouse, J. E. and Moore, G. R. (1982) Reduction of water with zinc for hydrogen isotope analysis. Anal. Chem. 54, 993-995.

Horita, J. (1989) Stable isotope fractionation factors of water in hydrated saline mineral-brine systems. Earth Planet. Sci. Lett. 95, 173-179. 
Horita, J., Ueda, A., Mizukami, K. and Takatori, I. (1989) Automatic $\delta \mathrm{D}$ and $\delta^{18} \mathrm{O}$ analyses of multiwater samples using $\mathrm{H}_{2}$ - and $\mathrm{CO}_{2}$-water equilibration methods with a common equilibration set-up. Appl. Radiat. Isot. 40, 801-805.

Kakiuchi, M. (1988) Fractionation of hydrogen isotopes in aqueous lithium chloride solutions. Z. Naturforsch. 43a, 449-453.

Kakiuchi, M. (1994) Temperature dependence of fractionation of hydrogen isotopes in aqueous sodium chloride solutions. J. Solut. Chem. 23, 1073-1087.

Kakiuchi, M. (1997a) Fractionation of hydrogen isotopes in water vapor-saturated solution-crystalline hydrate systems. Geochem. Soc. Japan Abst. Prog., p. 251 (in Japanese).

Kakiuchi, M. (1997b) Hydrogen isotope fractionation in aqueous alkali halide solutions. Z. Naturforsch. 52a, 811-820.

Kakiuchi, M. (1999a) Fractionation of hydrogen isotopes in crystalline hydrate-water systems. International Conference of Stable Isotopes and Isotope Effect Abst. Prog., p. A18.

Kakiuchi, M. (1999b) Fractionation of hydrogen isotopes in hydrous mineral-water systems. Geochem. Soc. Japan Abst. Prog., p. 57 (in Japanese).

Kakiuchi, M. and Matsuo, S. (1979) Direct measurements of $\mathrm{D} / \mathrm{H}$ and ${ }^{18} \mathrm{O} /{ }^{16} \mathrm{O}$ fractionation factors between vapor and liquid water in the temperature range from 10 to $40^{\circ} \mathrm{C}$. Geochem. J. 13, 307-311.

Kakiuchi, M., Abe, T. and Nakayama, H. (2001) D/H fractionation factor between water vapor and crystal water of copper chloride dihydrate: Statistical mechanical approach based on Raman spectra. Geochem. J. 35, this issue, 285-293.
Kita, I. and Matsuo, S. (1981) Intracrystalline site preference of hydrogen isotopes in the water of crystallization of copper sulfate pentahydrate. J. Phys. Chem. 85, 792-797.

Linke, W. F. (Seidell, A.) (1958) Solubilities of Inorganic and Metal-Organic Compounds: A Compilation of Solubility Data from the Periodical Literature. 4th ed., Vol I, p. 936, D.Van Nostrand.

Matsuo, S., Friedman, I. and Smith, G. I. (1972) Studies of quaternary saline lakes-I. Hydrogen isotope fractionation in saline minerals. Geochim. Cosmochim. Acta 36, 427-435.

Ohsumi, T. and Fujino, H. (1986) Isotope exchange technique for preparation of hydrogen gas in mass spectrometric D/H analysis of natural waters. Anal. Sci. 2, 489-490.

O'Neil, J. R. (1968) Hydrogen and oxygen isotope fractionation between ice and water. J. Chem. Phys. 72, 3683-3684.

Pradhananga, T. M. and Matsuo, S. (1985) D/H fractionation in sulfate hydrate-water systems. $J$. Phys. Chem. 89, 1869-1872.

Rolston, J. H., den Hartog, J. and Butler, J. P. (1976) The deuterium isotope separation factor between hydrogen and liquid water. J. Phys. Chem. 80, 1064 1067.

Sudzuki, N. (1987) A water conversion method for D/H ratio analyses and its accuracy. Geochem. J. 21, 29-33.

Ushiki, H. and Kakiuchi, M. (in preparation) Revised zinc batch method for $\mathrm{D} / \mathrm{H}$ ratio analysis of water.

Weston, R. E. (1955) Hydrogen isotope fractionation between ice and water. Geochim. Cosmochim. Acta 8, 281-284. 